\title{
RETRACTED ARTICLE: Chewing ability in an adult Chinese population
}

\author{
Qian Zhang • Dick J. Witter • Ewald M. Bronkhorst • \\ Nico H. J. Creugers
}

Received: 19 May 2011 / Accepted: 15 November 2011 /Published online: 2 December 2011

(C) The Author(s) 2011. This article is published with open access at Springerlink.com

This article has been withdrawn due to wrong content with serious consequences such as danger to people's health.
Open Access This article is distributed under the terms of the Creative Commons Attribution Noncommercial License which permits any noncommercial use, distribution, and reproduction in any medium, provided the original author(s) and source are credited.

This article has been withdrawn due to wrong content with serious consequences such as danger to people's health.

\section{Q. Zhang $(\square)$}

Department of Prosthetic Dentistry, Affiliated Hospital of Medical

School, Qingdao University,

Jiangsu Road 16\#,

Qingdao, People's Republic of China

e-mail: habebeq@hotmail.com

D. J. Witter - N. H. J. Creugers

Department of Oral Function and Prosthetic Dentistry,

College of Dental Science, Radboud University Nijmegen

Medical Centre,

Philips van Leydenlaan 25,

6525 EX, Nijmegen, The Netherlands

D. J. Witter

e-mail: d.witter@dent.umcn.nl

N. H. J. Creugers

e-mail: n.creugers@dent.umcn.nl

E. M. Bronkhorst

Department of Preventive and Restorative Dentistry,

College of Dental Science, Radboud University Nijmegen

Medical Centre,

Philips van Leydenlaan 25,

6525 EX, Nijmegen, The Netherlands

E. M. Bronkhorst

e-mail: e.bronkhorst@dent.umcn.nl 